\title{
Preliminary results of the coupled CWRF-GOSSYM system
}

\author{
Min Xu ${ }^{a^{*}}$, Xin-Zhong Liang ${ }^{a}$, Wei Gao ${ }^{b}, K$. Raja Reddy ${ }^{c}$ \\ James Slusser ${ }^{\mathrm{b}}$, Kenneth Kunkel ${ }^{\mathrm{a}}$ \\ a Illinois State Water Survey, University of Illinois at Urbana-Champaign, USA \\ ${ }^{\mathrm{b}}$ The USDA UV-B Monitoring and Research Program, Colorado State University, USA \\ ${ }^{\mathrm{c}}$ Department of Plant and Soil Sciences, Mississippi State University, USA
}

\begin{abstract}
GOSSYM is a comprehensive crop growth model that has been continuously developed since the late 1970s and widely applied to assist cotton growers, crop consultants, and researchers. The state-of-art CWRF (Climate-Weather Research and Forecasting model) demonstrated skillful simulations of regional water and energy cycle processes that are keenly important to cotton growth. This study focuses on coupling GOSSYM and CWRF to study crop-climate interactions. The coupling procedures include (1) recoding the GOSSYM to follow the CWRF F90 modular implementation; (2) replacing the soil dynamic module of the GOSSYM with the CWRF-predicted soil temperature and moisture while integrating the crop field management or cultural practice component (e.g., irrigation, tillage); (3) providing the GOSSYM with surface air temperature, precipitation, and surface solar radiation from the CWRF; (4) constructing crop height and coverage, leaf and stem area indices, greenness and root profile from the GOSSYM as inputs for the CWRF to represent the crop feedback on solar albedo and infrared emissivity, precipitation interception, and evapotranspiration. This study presents the preliminary results of the GOSSYM driven by the CWRF simulated climate conditions and discusses the model performance on cotton yield, leaf area index and height and their responses to water stress under the irrigation and non-irrigation conditions.
\end{abstract}

Keyword: CWRF, GOSSYM, crop-climate interactions

\section{INTRODUCTION}

Climate impacts crop production by modifying the biophysical environment in which crops grow. Temperature is one of the most important variables controlling crop growth and phenology while rainfall and atmosphere-soil interactions play determining roles in crop productivity ${ }^{18}$. On the other hand, regional climate processes, including precipitation, evapotranspiration and radiation are controlled by live and dead vegetation. Therefore, it becomes logical and necessary to couple climate and crop models to better represent the nonlinear interactions between regional climate, ecosystem, and agricultural crops.

GOSSYM is a leading crop growth model that has been continuously developed since late 1970s and widely applied in cotton production to support crop management decisions. The model structures, algorithms and applications have been well documented ${ }^{1,15,16,19}$. It can simulate the dynamic mass balance and distribution of carbon, nitrogen, and water within the plant and soil root-zone. It predicts crop and soil responses to environmental variables such as solar radiation, temperature, rain/irrigation, and wind, as well as to variations in soil properties and cultural practices. The model estimates plant growth and development rates by first calculating the potential rates from temperatures and then correcting them to account for environmental stresses, such as water, carbohydrate, nitrogen and heat.

The CWRF is the climate extension of the WRF (Weather Research and Forecasting model), which is built upon the most advanced supercomputing technologies and promises great efficiency in computation and flexibility in new module incorporation ${ }^{11}$. In particular, this extension has incorporated a state-of-the-art Common Land Model ${ }^{3}$ (CLM) to predict temperature, moisture, snow and surface fluxes of soil and vegetation. The major CLM characteristics include: a 10-layer prediction of soil temperature and moisture; a 5-layer prediction of snow processes (mass, cover, age); an explicit treatment of liquid and ice water mass and their phase change in soil and snow; a runoff parameterization based

\footnotetext{
* Corresponding author address: Dr. Min Xu, Illinois State Water Survey, University of Illinois at Urbana-Champaign, 2204 Griffith Dr., Champaign, IL 61820-7495. E-mail:minxu@uiuc.edu
}

Remote Sensing and Modeling of Ecosystems for Sustainability II, edited by Wei Gao, David R. Shaw, Proc. of SPIE Vol. 5884 (SPIE, Bellingham, WA, 2005) · 0277-786X/05/\$15 · doi: 10.1117/12.621017 
on the TOPMODEL concept; a canopy photosynthesis-conductance scheme that describes the simultaneous transfer of $\mathrm{CO}_{2}$ and water vapor into and out of vegetation; a tiled treatment of subgrid fraction of energy and water balance; highresolution geographic distributions of land cover, vegetation, root and soil properties. The latest version CLM3.0 incorporates several important updates and new modules ${ }^{4}$. A more realistic representation of soil and canopy properties has been implemented ${ }^{11}$ using the PSU 1-km dataset for the continental United States multi-layer soil characteristics (the bedrock depth and sand/clay profiles), the USGS 1-km satellite remote sensing data for land cover (vegetation type) and time-varying greenness and LAI. Due to the great influences of surface albedo on surface energy budget and partitioning, which in turn change hydrological processes, and modify the absorption of photosynthetically active radiation (PAR), a new dynamic-statistical parameterization of snow-free land surface albedo has been developed, and implemented into the CWRF, using the Moderate Resolution Imaging Spectroradiometer (MODIS) products ${ }^{10,12}$. The solar ultraviolet-B (UVB) radiation has increased due to human activity in recent years, and has impacts on cotton growth which includes reducing the canopy photosynthesis and cotton leaf area expansion and stem elongation ${ }^{20}$. The NCAR TUV solar radiation transfer model ${ }^{14}$ has been recoded to follow the CWRF F90 standard and is being validated against the USDA UV-B network measurements. It will be integrated to CWRF with the 3-D UV-Canopy module to predict the UV radiation below canopy ${ }^{7,8}$ and UV-B stress on cotton growth.

The CWRF has demonstrated great capability and skill in simulating regional water and energy cycle processes that are keenly important to cotton growth ${ }^{13}$, while the GOSSYM recoding and coupling with the CWRF has just been completed. It is crucial at this stage to first examine if the recoded GOSSYM and the newly developed interfaces work properly before the full coupled CWRF-GOSSYM simulation is conducted. This study presents preliminary results where the new GOSSYM module is driven (thus an offline test without feedback) by the CWRF simulated climate conditions for the growing season of 1993 in the United State cotton belt.

\section{CWRF-GOSSYM COUPLING}

\subsection{Recoding GOSSYM to follow the CWRF F90 modular design}

The original GOSSYM source code was written in the F77 standard and departs substantially from the CWRF F90 modular designs. The F77 standard has numerous apparent shortcomings as compared with the F90. In particular, the F77 does not include the complex data type to describe the hierarchical structure of plant organic parts nor dynamic memory allocation which is desired for actual objectives with variable dimension size such as the growing leaf, stem, root and boll. In addition, the original code was written for simulation at a single site and not suitable for coupling with the CWRF where simultaneous calculations over a large array of geographically distributed grids are necessary. As such, the first step before the coupling is to recode GOSSYM to follow the CWRF F90 modular design.

Several new features of F90 were incorporated in the GOSSYM recoding process. First, derived data types were introduced to make the model data structure more robust, flexible and extendable. Plants such as cotton have a root system and a main stem based on it. The main stem attaches leaves and branches that bear next level leaves, branches, squares and bolls. In order to describe this hierarchical relationship, the GOSSYM data structures were rebuilt based on the cotton organic structures and different mass balance types. New derived data types such as leaf, stem, root, and boll were defined to hold all the model status variables that are related to the respective plant organs. Derived data types were also added for mass balance of nitrogen, carbohydrate and water. These derived data types are connected by defining pointers to point at each other. Second, pointers were instructed to connect model derived type data and allocate dynamic array. Third, the F90 modular structure was implemented to systematically separate the model functions and group the same categorical procedures and corresponding data into a single module. The main advantages of this modular design facilitate (1) easy knowledge integration from different disciplines, (2) flexibility for model updates by specific modules being added, modified or substituted with little effect on others, and (3) efficient coupling with other models.

There are 16 distinct modules, including driver, weather, soil, root, stem, leaf, boll, square, stress, growth, and physiology. The driver is the key module that couples CWRF with GOSSYM. In particular, it takes surface air temperature, precipitation, and surface solar radiation from the CWRF and feedbacks crop height and coverage, leaf and stem area indices, greenness, and root profile from the GOSSYM. This module replaces original subroutines CLYMAT and TMPSOL. The old plant physiology subroutines GROWTH and RUTGRO are separated into the modules of leaf, stem, root, square and boll. We plan to improve these modules for cotton in arid and semi-arid regions by the Cotton $2 \mathrm{k}$ model $^{*}$. As discussed later, the GOSSYM poorly simulates cotton yields in Arizona and California. The Cotton2k has

\footnotetext{
${ }^{*}$ Marani 2004, http://departments.agri.huji.ac.il/plantscience/cotton/Cotton2KSource.htm
} 
shown promising skill for pima cottons in dry conditions and also uses an hourly integration interval instead of a daily step in GOSSYM, more attractive for coupling with the CWRF.

\subsection{Ecological input}

In United States, cotton usually is grown in the southern states, especially in the Texas high plain, the irrigated valleys of Arizona and California, and the Mississippi Delta. These regions comprise the U.S. cotton belt which is the main study area for the coupled CWRF-GOSSYM system.

Figure 1 shows the cotton planting area and observed harvest yields (unit: pound per acre, lb/ac) in CWRF grids $(30 \mathrm{~km} \times 30 \mathrm{~km})$ which are derived from USDA (United States Department of Agricultural), NASS (National Agricultural Statistics Service) Crops County Data (CCD) 1993-1994* . The cotton yield is highest (larger than $900 \mathrm{lb} / \mathrm{ac}$ ) in the western states (CA, AZ and NM), and has relative smaller values (less than $400 \mathrm{lb} / \mathrm{ac}$ ) in the Texas high plains. The southeastern and mid-southern states of the cotton belt have average yields of $600 \mathrm{lb} / \mathrm{ac}$ with larger yields and planting area in Mississippi Delta.

The newly coded GOSSYM with the capability of full coupling with the CWRF was run offline on the CWRF 30-km grid mesh ${ }^{13}$, where the common agricultural practice data were specified; and daily climatic conditions were provided by the CWRF integration during the 1993 growing season. The initial soil fertility status (such as residual nitrogen, organic matter content), water content and soil physical and hydraulic properties in each grid was based on the CWRF built-in surface boundary conditions ${ }^{11}$. The common agricultural inputs include: (1) the planting date in each grid based on the statistical data from NASS (see Table 1), where the longest growing season runs from April 1 to October 30; (2) the row

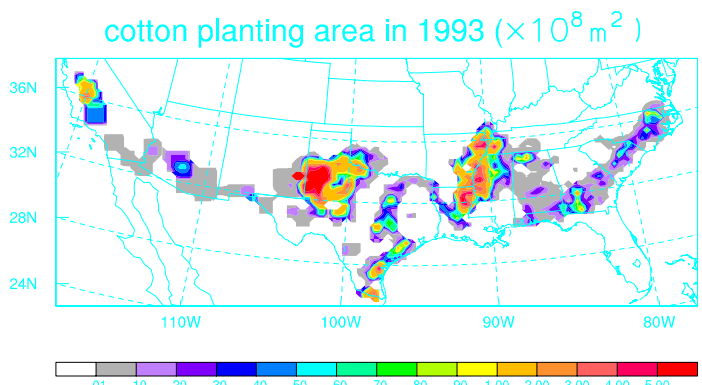

(b) harvest cotton yield in 1993 (Ib/ac)

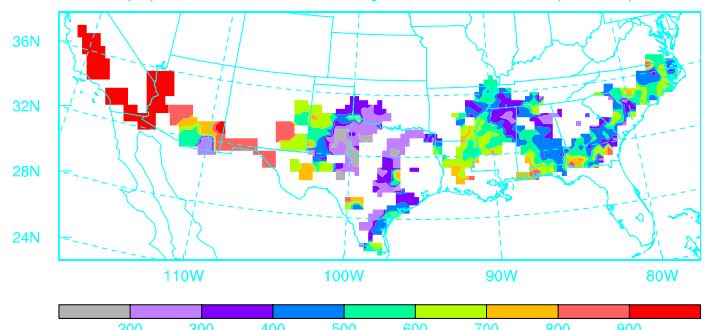

Figure1. Geographic distributions of the cotton planting area and harvest yield in the CWRF grid. spacing specified as 38 inch $(0.96 \mathrm{~m})$ with a population of 50896 plants per acre; (3) the cotton variety chosen as "mid"; (4) no plant growth regulator (PGR) applied; and (5) two irrigation options tested to study the cotton responses to water stress, i.e., rain-fed (non-irrigation) versus mild water stress (irrigation applied once water stress factor falling below $0.75)$.

\subsection{Meteorological simulator}

Instantaneous surface air temperature, soil layer temperature, net radiation flux, precipitation and surface wind simulated by the CWRF provide meteorological inputs for the GOSSYM. In the future, the evapotranspiration from leaf and soil as simulated by the CWRF based on a more comprehensive physically-based formulation will also be directly used in the GOSSYM to replace the empirical calculations. Since the CWRF uses an integration time step of 2 minutes, much shorter than the daily GOSSYM calculation, the coupling is activated at the end of each day. The instantaneous CWRF outputs are averaged for daytime and nighttime values (e.g., temperature) or accumulated for daily totals (e.g., solar net radiation and precipitation) to produce the GOSSYM inputs. In the future, we plan to use an hourly time step to improve the coupling, especially when the Cotton $2 \mathrm{k}$ is incorporated into the GOSSYM. Figure 2 compares the observed and CWRF-simulated surface air temperature

\footnotetext{
${ }^{*}$ http://usda.mannlib.cornell.edu/data-sets/crops/9X100/D/
}

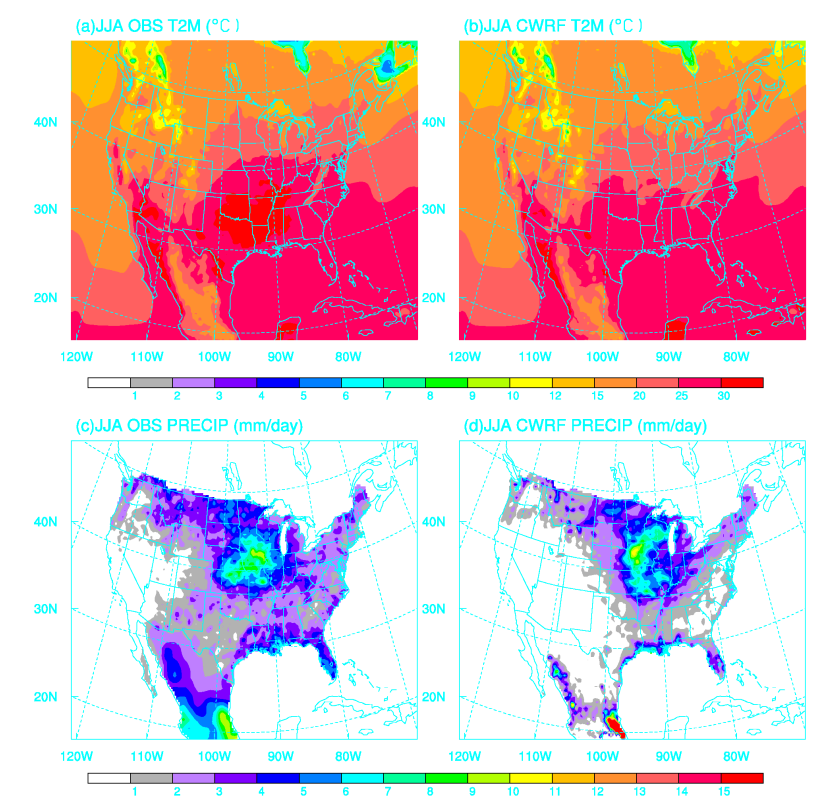

Figure 2. Observed (OBS, left) and simulated (CWRF, right) surface air temperature $\left({ }^{\circ} \mathrm{C}\right)$ and precipitation $(\mathrm{mm} /$ day) averaged in the summer (June-July-August) of 1993. 
and precipitation averaged in the 1993 summer. The CWRF simulation agrees well with observations, especially in the Midwest. Over the cotton belt, the simulation is reasonable except for slightly cooler temperatures in TX, OK, AR and LA and less precipitation overall. Most recently, the CWRF has been significantly improved in both temperature and precipitation ${ }^{13}$. We anticipate that more realistic coupling will be achieved when the new CWRF and Cotton $2 \mathrm{k}$ are used.

\section{RESULTS}

Figures 3 and 4 show simulated yield, boll weight, plant height and LAI for irrigated condition and non-irrigated conditions, respectively. The overall water stress factor is much larger under irrigation (Fig. 3b) than non-irrigation (Fig. $4 \mathrm{~b})$. Accordingly, the cotton yield, LAI, plant height, number and weight of open bolls per plant are all higher under the irrigation (Fig. 3a,c-f) than non-irrigation (Fig. 4a,c-f) condition. Under the irrigation condition, cotton growth is nearly free of water stress, with a water stress factor larger than 0.9 in the south central and southeastern parts of the cotton belt and around 0.7-0.8 in the southwestern area. Although the plant height and LAI are less in the southwestern states (CA, AZ) than the southeastern states, the cotton yield per acre is larger than in the former due to the higher number and weight of open bolls. Under the non-irrigation condition, the water stress on cotton growth is relatively severe depending on regional precipitation availability, particularly in the southwestern states (CA, AZ, NM) where dry weather prevails and the water stress factor is smaller than 0.5 . The severe water stress greatly reduces the LAI, cotton height, boll weight and number of open bolls and consequently leads to very low yield (less than $200 \mathrm{lb} / \mathrm{ac}$ ).

Compared with observations, the simulated yields in the southwestern states (CA, AZ, and NM) are more realistic under the irrigation than non-irrigation condition; the reverse is true for the south central land and southwestern states of the cotton belt (Table 1). According to the USDA CCD, irrigation is applied in actual agricultural operations mostly over the southwestern states (CA, AZ, NM), while other states of the cotton belt are basically rain-fed. Thus the modeling system captures the major processes for cotton growth with skillful cotton yield simulation under different irrigation or water stress conditions.

Figure 5 shows the time evolution of spatial correlation of the highest cotton yield with local daily maximum and minimum temperature, precipitation, and LAI under the irrigation and non-irrigation conditions. The yield has a stronger correlation with temperature than precipitation. Interestingly, the yield has positive (negative) correlations with daily maximum (minimum) temperature under the irrigation condition. These relationships are reversed under the nonirrigation condition. The maximum absolute correlation (positive or negative) reaches 0.6 and appears after 30-60 days from the occurrence of the first square. Meanwhile, under the non-irrigation condition, the cotton yield correlation with LAI is highly positive (up to 0.8 ) after 60-90 days from the appearance of the first square and negative (down to -0.6) just before the final harvest. This relationship, when validated by observations, has important implication: the LAI information during the period of 60-90 days after the first square, such as measured by MODIS or other satellites, can be used to effectively predict the local cotton yield. This predictive potential, however, is limited to the non-irrigation condition since no significant correlation is found when irrigated.

In summary, the GOSSYM has been recoded to follow the F90 modular designs and coupled with the CWRF. The preliminary result has demonstrated that the GOSSYM, when driven by the CWRF meteorology (i.e., offline without feedback), performs reasonably well, especially capturing the cotton growth responses to water stress. These responses include: (1) reduced or ceased leaf expansion; (2) less vegetative growth with shorter plant height; (3) decreased plant photosynthesis due to smaller LAI and plant height; (4) increased square and young boll shedding; and (5) smaller boll carry capacity. Further modification, validation and calibration of the coupled CWRF-GOSSYM system are in progress to improve the model performance and predictive skill for the cotton life cycle and understanding of crop-climate interactions.

Acknowledgements. This research was partially supported by the United States Department of Agriculture UV-B Monitoring and Research Program grant to University of Illinois at Urbana-Champaign (AG CSU G-1502-5). The data processing was mainly conducted on the UIUC/NCSA supercomputing facility. The views expressed are those of the authors and do not necessarily reflect those of the sponsoring agencies or the Illinois State Water Survey. 
Table 1 Cotton planting date and Yield from observation and simulation

\begin{tabular}{c|cccc}
\hline State & $\begin{array}{c}\text { Planting } \\
\text { Date }\end{array}$ & $\begin{array}{c}\text { 1993 Harvest } \\
\text { Yield(lb/ac) }\end{array}$ & $\begin{array}{c}\text { Simulated Yield } \\
\text { (Irrigation, lb/ac) }\end{array}$ & $\begin{array}{c}\text { Simulated Yield } \\
\text { (Non-irrigation, } \\
\text { lb/ac) }\end{array}$ \\
\hline AL & Apr. 24 & 510.13 & 630.11 & 504.65 \\
AZ & Apr. 01 & 877.05 & 892.70 & 166.80 \\
AR & May 01 & 504.00 & 699.26 & 590.77 \\
CA & Apr. 15 & 1139.50 & 892.06 & 312.05 \\
FL & Apr. 15 & 642.26 & 685.32 & 628.13 \\
GA & Apr. 25 & 490.75 & 679.72 & 516.12 \\
LA & Apr. 26 & 646.98 & 869.76 & 752.46 \\
MS & Apr. 28 & 531.91 & 764.47 & 614.28 \\
MO & May 05 & 528.25 & 633.29 & 594.88 \\
NM & Apr. 20 & 756.30 & 777.43 & 86.82 \\
NC & May 01 & 540.95 & 654.43 & 508.57 \\
OK & May 20 & 334.23 & 768.79 & 426.08 \\
SC & May 01 & 442.10 & 671.65 & 491.16 \\
TN & May 05 & 450.59 & 574.75 & 472.35 \\
TX & May 05 & 422.04 & 861.57 & 418.73 \\
VA & Apr. 10 & 624.47 & 778.82 & 551.04 \\
\hline
\end{tabular}

(a) simulated cotton yield in 1993 (lb/ac)
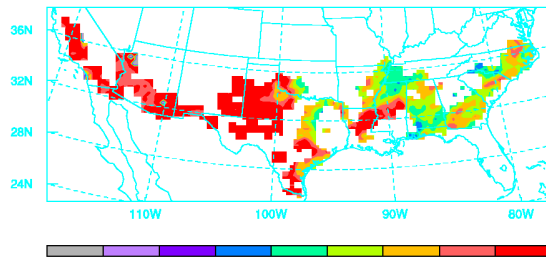

(c) simulated cotton height (in)
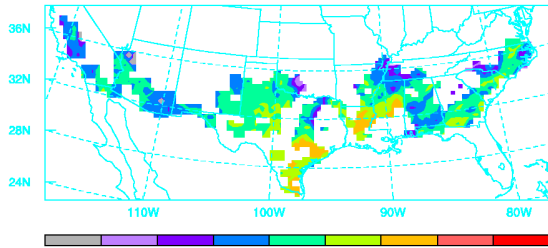

( $\ominus$ ) simulated maximum cotton LAI

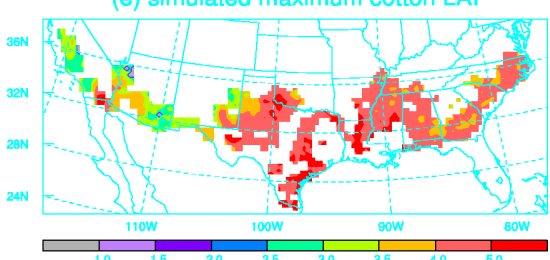

(b) average water stress factor

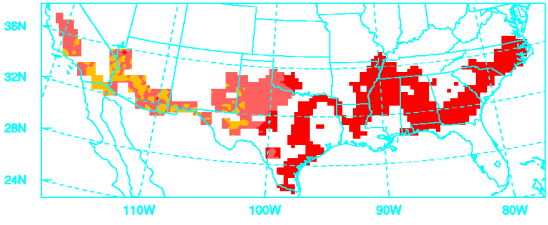

(d) simulated open boll weight (g)

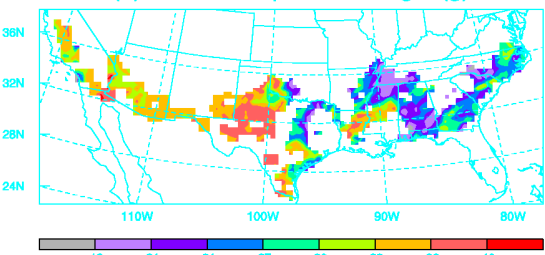

(f) simulated number of open boll

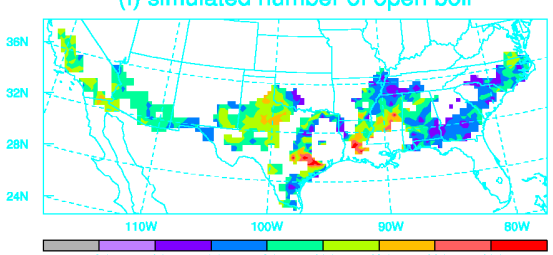

Figure 3. Simulated cotton yield (a), water stress factor (b), plant height(c), open boll weight (d), LAI (e) and open boll number (f) under the irrigation condition in 1993. 
(a) simulated cotton yield in $1993(\mathrm{lb} / \mathrm{ac})$

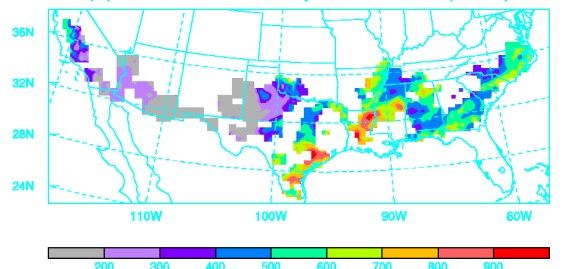

(c) simulated cotton height (in)

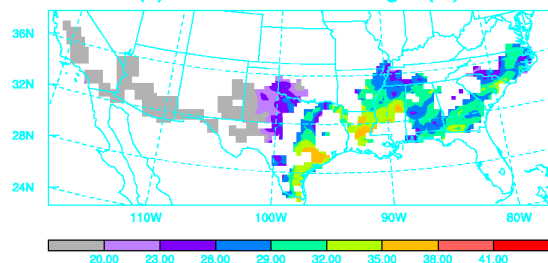

(e) simulated maximum cotton LAI

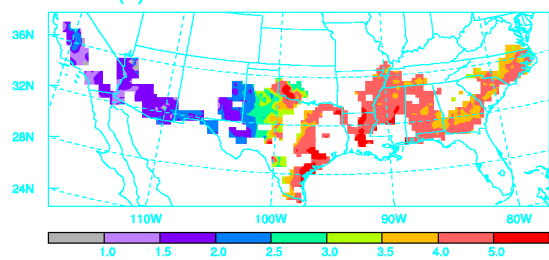

(b) average water stress factor

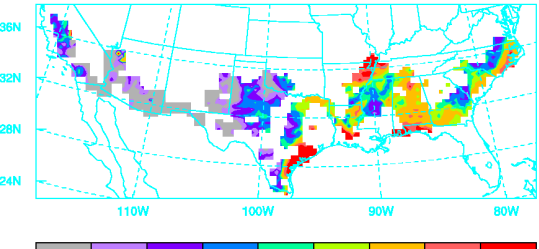

(d) simulated open boll weight (g)

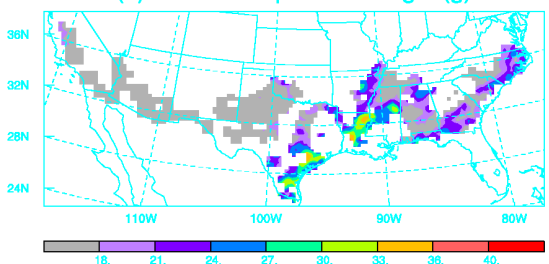

(†) simulated number of open boll

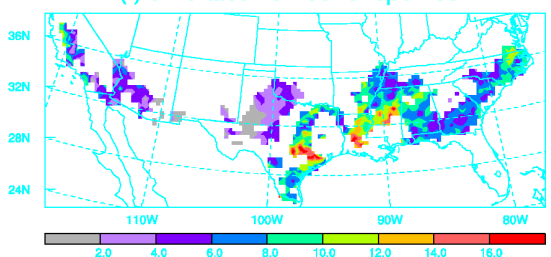

Figure 4. Simulated cotton yield (a), water stress factor (b), plant height(c), open boll weight (d), LAI (e) and open boll number (f) under the non-irrigation condition in 1993.
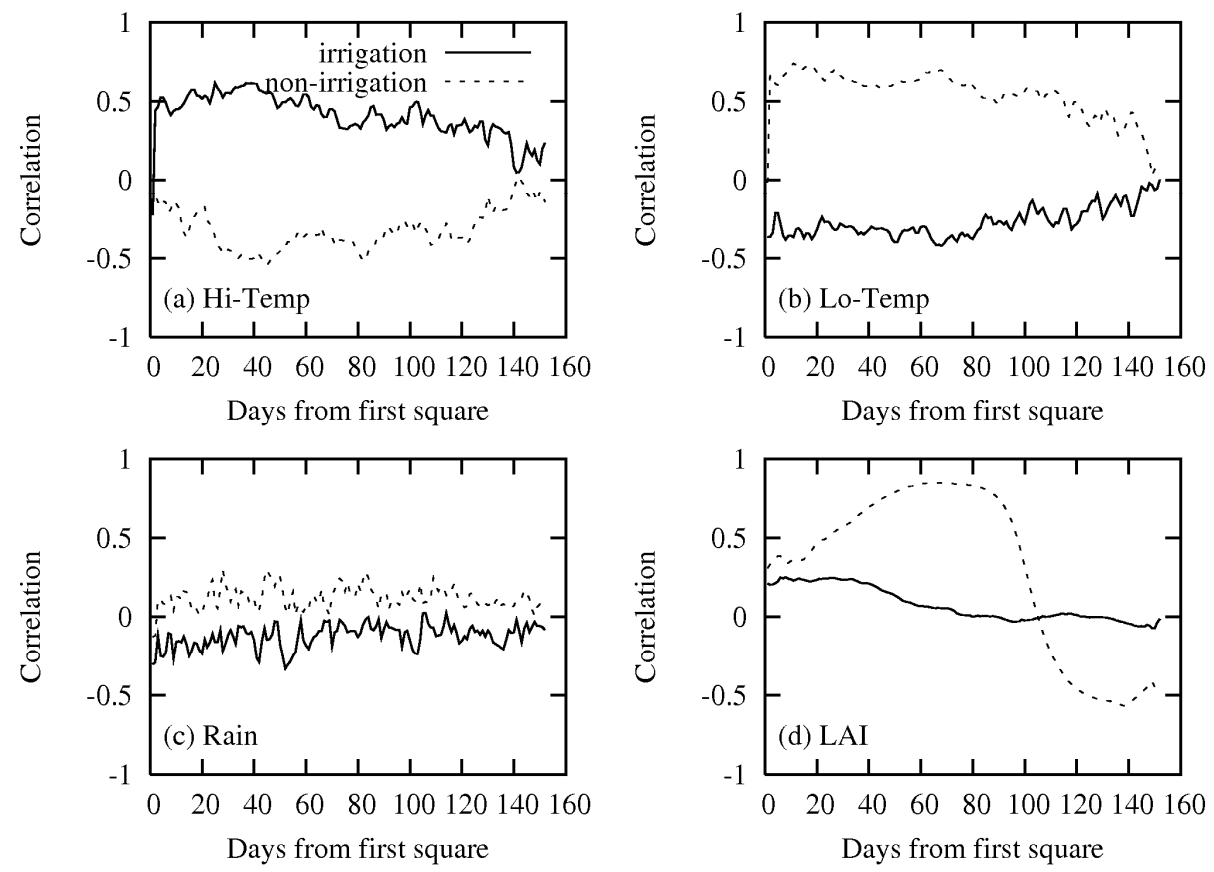

Figure 5. Time evolution (from the time of the first square) of the correlation of the highest cotton yield with local daily maximum (a) and minimum (b) temperature, total precipitation (c), and leaf area index (d). 


\section{REFERENCES}

1. Baker, D.N., J.R. Lambert, and J.M. McKinion, 1983: GOSSYM: A Simulator of Cotton Crop Growth and Yield. SC Agric. Expt. Stn. Tech. Bull. No.1089, Clemson, South Carolina, USA.

2. Choi, H.I., P. Kumar, and X.-Z. Liang, 2005: Development of a 3-D volume averaged soil moisture transport model (VAST) with a parameterization of subgrid topographic effects. Advances in Water Resources (to be submitted soon).

3. Dai, Y., X. Zeng, R.E. Dickinson, I. Baker, G. Bonan, M. Bosilovich, S. Denning, P. Dirmeyer, P. Houser, G. Niu, K. Oleson, A. Schlosser, and Z.-L. Yang, 2003: The Common Land Model (CLM). Bull. Amer. Meteor. Soc., 84, 1013-1023.

4. Dai, Y., X.-Z. Liang, and R.E. Dickinson, 2005: Common Land Model version 3.0 in couple with the ClimateWeather Research and Forecasting model (CWRF). J. Climate (in preparation).

5. Dickinson, R.E., M. Shaikh, R. Bryant, and L. Graumlich, 1998: Interactive canopies for a climate model. $J$. Climate, 11, 2823-2836.

6. Dickinson, R.E., J.A. Berry, G.B. Bonan, G.J. Collatz, C.B. Field, I.Y. Fung, M. Goulden, W.A. Hoffman, R.B. Jackson, R. Myneni, P.J. Sellers, and M. Shaikh, 2002: Nitrogen controls on climate model evapotranspiration. J. Climate, 15, 278-295.

7. Gao, W., R.H. Grant, G.M. Heisler, and J.R. Slusser, 2002: A Geometric utraviolet-B radiation transfer model applied to vegetation canopies. Agronomy Journal, 94, 475-482.

8. Grant, R.H., G.M. Heisler, and W. Gao. 2002. Estimation of pedestrian level UV exposure under trees. Photochem Photobiol., 75, 369-376.

9. Kumar, P., 2004: Layer averaged Richards equation with lateral flow. Advances in Water Resources, 27(5), $521-531$.

10. Liang, X.-Z., M. Xu, W. Gao, K.E. Kunkel, J. Slusser, Y. Dai, and Q. Min, 2004: New land surface albedo parameterization based on MODIS data: A preliminary result. In Remote Sensing and Modeling of Ecosystems for Sustainability. W. Gao and D. Shaw (Eds.), Vol. 5544, SPIE Press (Bellingham, WA) pp. 55-60.

11. Liang, X.-Z., H. Choi, K.E. Kunkel, Y. Dai, E. Joseph, J.X.L. Wang, and P. Kumar, 2005a: Development of the regional climate-weather research and forecasting model (CWRF): Surface boundary conditions. Illinois State Water Survey Scientific Research, ISWS SR 2005-01, 32 pp. [Available at http://www.sws.uiuc.edu/pubs/pubdetail.asp?CallNumber=ISWS+SR+2005\%2D01].

12. Liang, X.-Z., M. Xu, W. Gao, K.E. Kunkel, J. Slusser, Y. Dai, Q. Min, P.R. Houser, M. Rodell, C.B. Schaaf, and F. Gao, 2005b: Development of land surface albedo parameterization bases on Moderate Resolution Imaging Spectroradiometer (MODIS) data. J. Geophys. Res., 110, D11107, doi:10.1029/2004JD005579.

13. Liang, X.-Z., M. Xu, J. Zhu, K.E. Kunkel, and J.X.L. Wang, 2005c: Development of the regional climateweather research and forecasting model (CWRF): Treatment of topography. In Proceedings of 2005 WRF/MM5 User's Workshop, Boulder, CO, June 27-30, 5 pp.

14. Madronich, S.,1993: UV radiation in the natural and perturbed atmosphere. In Environmental Effects of UV (Ultraviolet) Radiation, M. Tevini (Ed.), Lewis Publisher, Boca Raton, pp. 17-69.

15. McKinion, J.M., D.N. Baker, F.D. Whisler, J.R. Lambert, 1989: Application of GOSSYM/COMAX system to cotton crop management. Agric. Sys., 31, 55-65.

16. Reddy, K.R., H.F. Hodges, and J.M. McKinion, 1997: Crop modeling and applications: A cotton example. $A d v$. Agron., 59, 225-290.

17. Reddy, K.R., H.F. Hodges, and B.A. Kimball, 2000: Crop ecosystem responses to climatic change: Cotton. In Climate Change and Global Crop Productivit, K.R. Reddy and H.F. Hodges (Eds.), CABI Publishing, CAB International, Wallingford, Oxon OX10 8DE, UK. pp. 161-187.

18. Reddy, K.R., P.R. Doma, L.O. Mearns, M.Y.L. Boone, H.F. Hodges, A.G. Richardson, and V.G. Kakani, 2002a: Simulating the impacts of climate change on cotton production in the Mississippi Delta. Climate Research, 22, 271-281.

19. Reddy, K.R., V.G. Kakani, J.M. McKinion, and D.N. Baker, 2002b: Applications of a cotton simulation model, GOSSYM, for crop management, economic and policy decisions. In Agricultural System Models in Field Research and Technology Transfer, L.R. Ahuja, L. Ma, and T.A. Howell (Eds.), CRC Press, LLC, Boca Raton, FL, USA, pp. 33-73.

20. Reddy K.R., V.G. Kakani, D. Zhao, A.R. Mohammed, and W. Gao. 2003. Cotton responses to ultraviolet-B radiation: experimentation and algorithm development. J. Agric. Forest Meteorol. 120: 249-266. 